\title{
A Study on the Influence of Entrepreneurial Intention of College Students Exerted by the Entrepreneurial Education in Higher Institutions
}

\author{
Zhang Ning, ${ }^{1, *}$, Jiang Hua ${ }^{1,2}$ \\ ${ }^{1}$ College of Management, Harbin Institute of Technology, Harbin, China \\ ${ }^{2}$ Harbin Institute of Technology, Harbin, China \\ Email address: \\ monica_ning@163.com (Zhang Ning) \\ ${ }^{*}$ Corresponding author
}

\section{To cite this article:}

Zhang Ning, Jiang Hua. A Study on the Influence of Entrepreneurial Intention of College Students Exerted by the Entrepreneurial Education in Higher Institutions. Science Innovation. Vol. 5, No. 1, 2017, pp. 21-26. doi: 10.11648/j.si.20170501.14

Received: January 17, 2017; Accepted: February 22, 2017; Published: March 3, 2017

\begin{abstract}
On the basis of the data collected from the 202 students in H University who engage in undergraduate, postgraduate, doctoral and EMBA programs respectively, in this paper the author mainly discussed in the relationship between the form and content of the implementation of the higher institution's entrepreneurial education and the specific dimensions of students' entrepreneurial intention. To put it into a specific way, the multiple linear regression analysis is conducted here, by which it is discovered that except the individual satisfaction, all of the rest variables do exert significant effect on students' entrepreneurial intention. For this reason, it is of urgent necessity for higher institutions to place more emphasis on entrepreneurial education.
\end{abstract}

Keywords: Entrepreneurial Education, Entrepreneurial Intention, Perceived Expectation, Perceived Feasibility

\section{高校创业教育对大学生创业意向影响的研究}

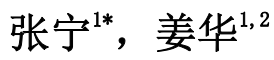

1管理学院, 哈尔滨工业大学, 哈尔滨, 中国

2高等教育研究所, 哈尔滨工业大学, 哈尔滨, 中国

邮箱

monica_ning@163.com（张宁）

摘要: 本文以H大 202 份本科、硕士、博士及以上、EMBA四个层次的学生调查样本为基础, 探讨了高校创业教育实施形 式和内容与创业意向具体维度之间的关系。通过多元线性回归分析, 发现除个体态度中满意度不显著外, 其他变量均 对创业意向起不同程度的显著作用。因此要高度重视高校创业教育。

关键词：创业教育，创业意向，感知期望，感知可行性 


\section{1. 引言}

在今天的知识经济、全球化的时代里, 创业扮演着重 要的角色, 被越来越多的人重视。在与创业活动有关的行 为中, 最重要的是创业意向, 而与创业意向密切相关的则 是创业教育。越来越多的学者研究创业教育与创业意向间 的关系。

创业教育是高校能够激发大学生的事业心和进取心 的一系列活动, 它的目标是培养具有创业精神和能力的人 才。在创业意向方面, 学者Bagozzi [1]、Thompson[2]等均 对其有明确的解释, 而本研究所指的创业意向则是潜在的 大学生创业者对未来创业行为的一种倾向, 这种倾向受自 身态度及外在相关因素的影响。创业意向在创业行为中处 于重要的地位, 有学者指出创业意愿也可以对创业行为进 行很好地预测, 因此创业意向作为创业行为的重要影响因 素。

本文在总结归纳以往研究基础上, 采用创业事件模型 (Shapero) 和计划行为理论 (Ajzen) 作为本文概念模型 的基础理论。其原因主要有两点：（1）态度、意愿与行为 的关系在两个模型中都有清晰地体现, 有利于本文总结创 业意愿的维度, 更好的进行实证研究; (2) 这两个模型已 经比较完善, 在现有的研究中得到了充分的检验与广泛地 运用。

创业事件模型 (SEE) 主要观点是创业是可以通过首创 精神、能力、管理、自主性和冒险精神相互作用影响的一 个事件。该模型认为创业意愿包括三个维度, 分别是：感 知期望、行为倾向和可行性认知。感知期望是创业前景好 坏对个体的吸引程度或者创办新企业对个人的吸引程度。 创业可行性是指创业行为是否可操作以及能够能实现, 以 及可操作及能实现的程度。而从事某一决策或行动的个体 倾向则代表创业倾向 [3]。1991年, 学者Icek Ajzen在《组 织行为和人类决策过程》中提出计划行为理论 (Theory of Planned Behavior), 即TPB理论。该理论的基础是Ajzen (1975) 和Fishbein (1980) 的理性行为理论 (Theory of Reasoned Action), 即TRA, 随后慢慢发展起来。Ajzen 认为人的行为处于控制之下, 并不是完全出于自愿。因此, $A j z e n$ 在创业计划模型基础上增加自我感知行为控制力这 一要素(Perceived Behavior Control)。简单来看, 在该 模型下创业行为的行为轨迹是 “信念一一态度一一意向一 一行为” $[4]$ 。

目前, 国内学者在创业意向、创业教育方面已经有多 方面的研究, 但主要是个人性格、个人背景和环境等与创 业意向之间影响的研究, 虽然提出创业教育是创业意向的 重要影响因素, 但还未进行深入的两者内容的机理作用。 主要原因是我国创业教育这一行为开始较晚, 重视创业教 育年份也较晚, 即创业教育与创业意向具体维度之间的关 系并不清晰。创业教育教学实施具体维度对创业意向的维 度之间、创业教育个体态度因素对创业意向的维度之间存 在着重要的影响路径, 但现有的相关研究中, 几乎未明确 提及或论证它们之间的关系。本文以创业事件模型和计划 行为理论的为理论依据, 在研究创业教育具体内容维度和 创业意向具体维度基础上, 研究二者之间具体内容的机理
作用关系。从而得出创业教育对创业意向的影响, 进一步 完善该方面的理论。

\section{2. 研究设计}

\section{1. 研究模型构建的维度取舍}

在创业意向方面, 本研究把感知期望和感知可行性作 为影响创业意向的维度指标。创业事件模型 (Model of the Entrepreneurial Event）里对创业意向产生作用的指标 主要有三个, 分别是感知期望、行为倾向和可行性认知。 而在TPB即计划行为理论模型中，对意愿直接产生影响的 因素是态度、主观规范性和感知可行性三个要素。根据本 文所研究的内容, 选取重叠的指标以便更好的研究。而对 于SEE模型中的行为倾向因素, 属于主观因素, 且易受其 他变量影响较大, 因此, 不作为本模型的因素列入创业意 向维度中。

在创业教育方面, 根据前人文献的相关研究, 本文研 究教学因素及学生个体态度对创业意向的影响。其中教学 因素包括创业教育师资、课堂教学、创业实践基地以及创 业计划模拟四个维度。学生个体态度因素考虑到创业教育 的学习效果很难测量和评估, 因此未将学习效果加入维度 中, 只选取包括个体参与度与参与创业教育满意度两个方 面维度。

\section{2. 理论假设的提出}

学者林崇德认为, 师资类型能够影响创业教育的教学 效果, 能够对学生的创业意向有显著的影响 [5]。创业教 育的教师如果对相关专业知识有深刻的理解与掌握, 有助 于学生对所学知识产生兴趣, 激发创业意向。因此可以提 出下列假设:

假设 1a: 创业教育师资类型与学生创业感知期望呈正 相关关系;

假设 $1 \mathrm{~b}$ : 创业教育师资类型与学生感知可行性呈正相 关关系。

课堂教学是知识显化的过程, 课堂教学内容的脉络清 晰程度以及基础知识的传达都会对学生产生影响。让学生 更加了解创业教育理论的基础知识有利于激发其感知期 望和感知可行性。而对于隐形知识而言, 学生是通过创业 实践基地和创业计划模拟习得的。通过创业实践基地和创 业计划模拟对创业的实践以及模拟, 让学生了解创业过程 中遇到的问题与挑战、创业流程以及创业所需具备的素质 与条件等等。学者斯滕伯格认为, 隐性知识对个体职业发 展有重要作用, 而获取隐性知识的渠道就是实践 [6]。因 此可以提出下列假设:

假设 $1 \mathrm{c}$ : 课堂教学内容与学生创业感知期望呈正相关 关系;

假设 $1 \mathrm{~d}$ : 课堂教学内容与学生感知可行性呈正相关关系;

假设 $1 \mathrm{e}$ : 创业实践基地的学习与学生创业感知期望呈 正相关关系;

假设 $1 \mathrm{~d}$ : 课堂教学内容与学生感知可行性呈正相关关系;

假设 $1 \mathrm{e}$ : 创业实践基地的学习与学生创业感知期望呈 正相关关系; 
假设 $1 \mathrm{f}$ : 创业实践基地的学习与学生感知可行性呈正 相关关系;

假设 1g: 大学生创业竞赛的学习与学生创业感知期望 呈正相关关系;

假设 $1 \mathrm{~h}:$ 大学生创业竞赛的学习与学生创业感知可行 性呈正相关关系。

有学者研究大学生创业教育参与度便是属于这种情 感性态度。因为大学生对创业这件事儿所反映的喜好或厌 恶程度, 在一定意义上可以反映在创业教育参与度上。而 创业行为态度可以反映出大学生对创业的看法或喜好厌 恶程度, 这可以清晰表明, 个人态度因素与创业意向间的 关系 (Lmhje and Frank, 2003) [7]。

假设 $2 \mathrm{a}$ : 学生创业教育参与度越高, 创业感知期望就 越强;

假设 $2 \mathrm{~b}$ : 学生创业教育参与度越高, 感知可行性就越强。

创业教育内容满意度直接影响个体对创业的态度和 后续行动。创业教育内容越丰富, 个体创业态度越积极 [8], 而个体的行为态度则是其行为意向的推动器 [9]。学者崔 涁在其研究中也指出大学生对创业教育的满意度就是大 学生在接受创业教育后对其期望和要求满足程度的主观
评价, 大学生对创业教育满意程度与高校创业教育质量有 相关关系 [10]。因此, 可以提出如下假设:

假设 $2 \mathrm{c}$ : 学生对创业教育内容的满意度越高创业感知 期望就越强;

假设 $2 \mathrm{~d}$ : 学生对创业教育内容的满意度越高感知可行 性就越强。

\section{3. 模型构建}

根据上述假设, 构建出本文的研究模型, 如图1。在 这个模型中, 创业教育是前置变量, 创业意向是结果变量, 本研究讨论二级因素前置变量的二级维度对结果变量二 级维度的影响。以SEE模型和TPB模型为基础的创业意向, 受感知期望和感知可行性两个维度的影响。值得注意的是 SEE中的行为倾向因素, 属于主观因素, 且易受其他变量 影响较大, 因此, 不作为本模型的因素列入创业意向维度 中。创业教育受教学因素和个体态度因素两方面的影响。 其中教学因素包含教育师资、课堂教学、创业实践基地、 创业计划模拟四个维度; 个体态度因素包含创业教育参与 度 [11] [12] [13]和对创业教育的满意度 [14]两个方面。

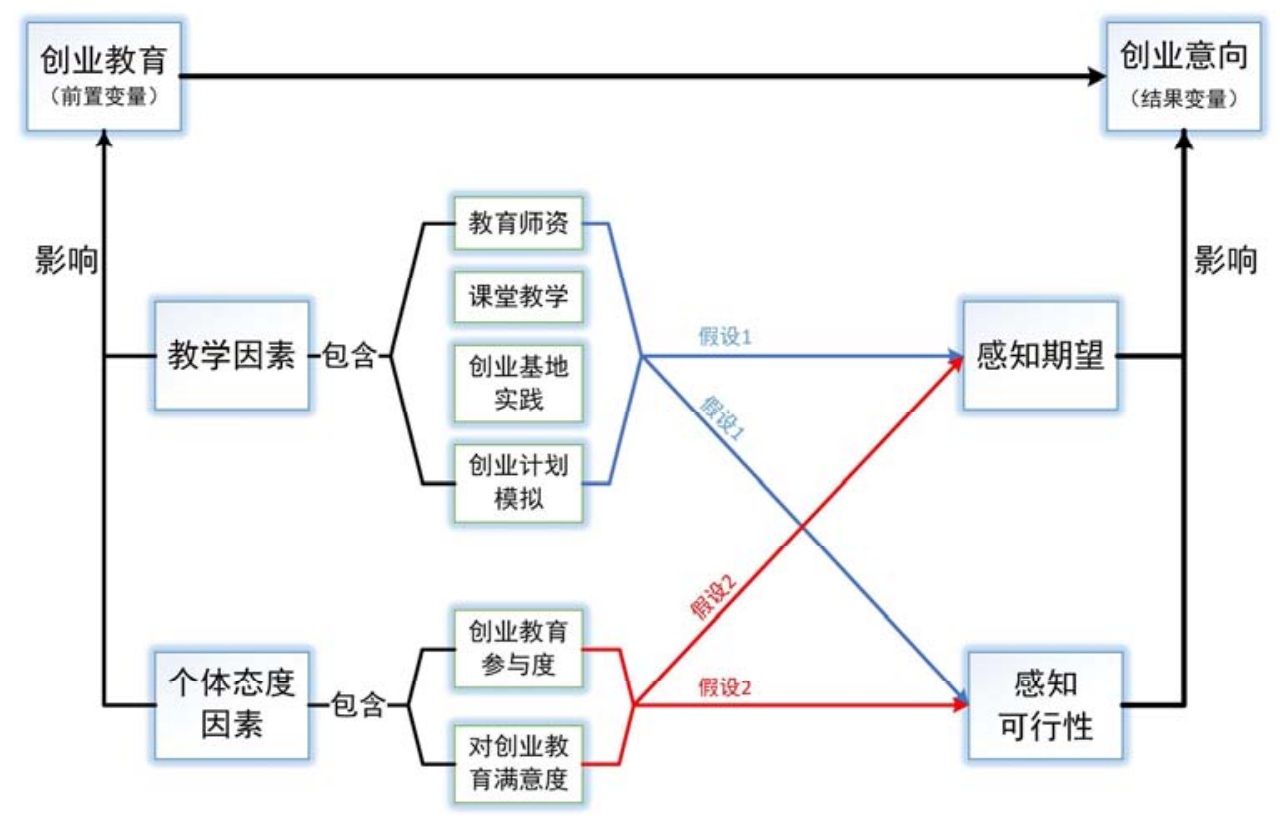

图1 本研究的研究模型。

\section{4. 数据收集}

本文通过对H大工科、理科、经管、文科其他等四大 学科方向, 包括本科、硕士、博士及以上、EMBA四个层次 的学生进行抽样问卷调查, 一共发出问卷 202 份, 其中回 收 202 份, 回收率 $100 \%$, 有效问卷 177 份, 有效率 $87 \%$ 。根 据小样本测试的结果, 剔除不适宜选项, 设计了一份包括 23 个题项的李克特五级量表。为保证回归分析的结果, 每 个因素都设置大于 3 个的题项。我们对 6 个自变量和 2 个因 变量进行同质信度Cronbach' s Alpha的计算, $\alpha$ 值为 0.894 。

\section{3. 实证研究}

\section{1 . 因子分析}

本研究采用探索性因子分析, 分别对学校教学因素和 个体态度因素进行效度检验, 采用最大正交旋转法提取相 关因子。在创业意向方面, Bartlett的球形检验显著性 $0.000, \mathrm{df}$ 值为 12 , 大约卡方值为 281.331 , KM0 值为 0.709 , 提取感知期望和感知可行性两个公因子。在教学因素方面, Bartlett球形检验大约卡方值为 844.274 , KM0值为 0.847 , $\mathrm{df}$ 值为 55 , 显著性 0.000 , 均达到标准, 提取教育师资、 课堂教学、创业实践基地和创业计划模拟四个因子。个人 
态度方面, Bartlett球形检验显著性0.000, KM0值为 0.712 , 提取创业教育参与度和对创业教育满意度两个因子。

\section{2. 相关性分析}

本研究采用Pearson简单相关系数进行研究, 各因素 相关性矩阵如表1。
从表中可得出感知期望、感知可行性与参与度、创业 竞赛、创业课程、实践基地和师资力量都成显著相关。满 意度和感知期望不存在相关的关系, 其皮尔森系数为 0.099, 满意度和感知可信性也不存在相关的关系, 其皮 尔森系数为 0.087 , 因此可以直接推断假设 $2 \mathrm{c}$ 和 $2 \mathrm{~d}$ 不支持, 但仍需要下一节的回归分析进行进一步的检验。

表1 各因素相关性矩阵。

\begin{tabular}{|c|c|c|c|c|c|c|c|c|c|}
\hline & & 满意度 & 参与度 & 创业竞赛 & 创业课程 & 实践基地 & 师资力量 & 感知期望 & 感知可行性 \\
\hline 满意度 & $\begin{array}{l}\text { 皮尔森相关性 } \\
\text { 显著性 }\end{array}$ & 1 & & & & & & & \\
\hline \multirow{2}{*}{ 参与度 } & 皮尔森相关性 & 0 & 1 & & & & & & \\
\hline & 显著性 & 1 & & & & & & & \\
\hline \multirow{2}{*}{ 创业竞赛 } & 皮尔森相关性 & $.172^{*}$ & .1 & 1 & & & & & \\
\hline & 显著性 & .022 & .184 & & & & & & \\
\hline \multirow{2}{*}{ 创业课程 } & 皮尔森相关性 & $.497^{* *}$ & .097 & 0 & 1 & & & & \\
\hline & 显著性 & 0 & .197 & 1 & & & & & \\
\hline \multirow{2}{*}{ 实践基地 } & 皮尔森相关性 & $.335^{* *}$ & .089 & 0 & 0 & 1 & & & \\
\hline & 显著性 & 0 & .239 & 1 & 1 & & & & \\
\hline \multirow{2}{*}{ 师资力量 } & 皮尔森相关性 & $.177^{*}$ & $.247^{* *}$ & 0 & 0 & 0 & 1 & & \\
\hline & 显著性 & .018 & .001 & 1 & 1 & 1 & & & \\
\hline \multirow{2}{*}{ 感知期望 } & 皮尔森相关性 & .099 & $.374^{* *}$ & $.431^{* *}$ & $.126^{*}$ & $.053^{*}$ & $351^{*}$ & 1 & \\
\hline & 显著性 & .999 & 0 & .019 & .095 & .059 & .045 & & \\
\hline \multirow{2}{*}{ 感知可行性 } & 皮尔森相关性 & .087 & $.453^{* *}$ & $.531^{* *}$ & $.135^{*}$ & $.041^{*}$ & $.211^{*}$ & 0 & 1 \\
\hline & 显著性 & .803 & .045 & .013 & .073 & .021 & .087 & 1 & \\
\hline
\end{tabular}

*. 相关性在0.05上显著 (双尾)。

**. 相关性在 0.01 上显著（双尾）。

\section{3. 相关性分析}

本研究的因变量是作为连续变量的大学生创业意向, 自变量是高校创业教育, 假设本研究的回归方程如下, 其 中 $\alpha$ 为常数项, $\beta_{i}$ 为回归系数, $Y$ 表示创业意向, $X_{i}$ 为 创业教育中影响创业意向的各个因素。

$$
Y=\alpha+\beta_{i} X_{i}(i=1,2, \cdots k)
$$

学校教学因素与大学生感知期望之间的关系四个预 测变量与感知期望之间调整后 $R$ 方为 0.816 , 四个变量共可
解释感知期望变量 $81.6 \%$ 的变异量。而从方差分析中可以 得到, 教学因素的四个维度对感知期望的回归通过了F检 验, 显著性为 0.049 , 达到显著。模型的VIF均是 1 到 2 之间, 变量间没有严重的共线性问题。由表中可知, 回归方程中 的 $\alpha$ 为 $3.696 \times 10^{-17}$, 显著性为 1.000 , 所以标准化系数为 0 , 四个变量均达到显著。四个变量的P均小于 $0.05, \beta$ 分 别为 $0.431 、 0.126 、 0.023 、 0.351$ 。创业竞赛、创业课程、 创业实践基地和师资水平的作用对大学生创业感知期望 均有显著正向作用, 假设 $1 \mathrm{~g} 、 1 \mathrm{c} 、 1 \mathrm{e} 、 1 \mathrm{a}$ 得到了验证。

表2 系数表A。

\begin{tabular}{|c|c|c|c|c|c|c|}
\hline \multirow{2}{*}{ 模型 } & \multicolumn{2}{|c|}{ 非标准化系数 } & \multirow{2}{*}{$\begin{array}{l}\text { 标准化系数 } \\
\text { Beta }\end{array}$} & \multirow{2}{*}{$\mathrm{T}$} & \multirow{2}{*}{ 显著性 } & \multirow{2}{*}{ VIF } \\
\hline & $\mathrm{B}$ & 标准差 & & & & \\
\hline 1（常数） & $3.696 \mathrm{E}-17$ & .074 & & .000 & 1.000 & \\
\hline 教学因素创业竞赛 & .431 & .074 & .431 & 3. 000 & .015 & 1. 000 \\
\hline 教学因素创业课程 & .126 & .074 & .126 & 2. 622 & .002 & 1. 000 \\
\hline 教学因素创业实践基地 & .053 & .074 & .053 & 2. 419 & .005 & 1. 000 \\
\hline 教学因素师资水平 & .351 & .074 & .351 & 2. 032 & .044 & 1. 000 \\
\hline
\end{tabular}

综上所述, 可以得到以下回归方程:

感知期望 $=0.431 \times$ 创业竞赛 $+0.126 \times$ 创业课程 $+0.053 \times$ 创业实践基地 $+0.351 \times$ 教师水平

学生态度因素与大学生感知期望之间的关系两个预 测变量与感知期望之间的调整后 $R$ 方为 0.769 , 共可解释感 知期望变量 $76.9 \%$ 的变异量。从方差分析中可以看出, 个 体态度的两个维度对感知期望的回归通过了 F检验, 显著 性为 0.000 小于 0.05 的显著水平, 表示回归模型解释变量 的水平达到显著。模型的VIF均是 1 到 2 之间, 变量间没有 严重的共线性问题。由表中的数据可以清楚看到, 回归方
程中的 $\alpha$ 为 $1.404 \times 10^{-17}$, 显著性为 1.000 , 标准化系数 为 0 , 个体态度因素达到了显著水平为 0.000 , 而满意度未 达到显著, $\mathrm{P}$ 值为 0.999 。个体态度参与度的作用对大学生 创业感知期望有显著正向作用, $\beta$ 为 $0.374, \mathrm{P}$ 小于 0.05 , 假设 $2 \mathrm{a}$ 得到了验证。个体态度满意度的作用对大学生创业 感知期望不显著, $\beta$ 为 $0.000, \mathrm{P}$ 大于 0.05 , 假设 $2 c$ 未得到 验证。 
表3 系数表B。

\begin{tabular}{|c|c|c|c|c|c|c|}
\hline \multirow{2}{*}{ 模型 } & \multicolumn{2}{|c|}{ 非标准化系数 } & \multirow{2}{*}{$\begin{array}{l}\text { 标准化系数 } \\
\text { Beta }\end{array}$} & \multirow{2}{*}{$\mathrm{T}$} & \multirow{2}{*}{ 显著性 } & \multirow{2}{*}{ VIF } \\
\hline & $\mathrm{B}$ & 标准差 & & & & \\
\hline 2（常数） & 1. $404 \mathrm{E}-17$ & .070 & & .000 & 1.000 & \\
\hline 个体态度满意度 & .000 & .070 & .000 & .002 & .999 & 1.000 \\
\hline 个体态度参与度 & 374 & .070 & .374 & 5.312 & .000 & 1.000 \\
\hline
\end{tabular}

综上所述，可以得到以下回归方程：

感知期望 $=0.000 \times$ 个体态度满意度 $+0.374 \times$ 个体态度参与度

学校教学因素与大学生感知可行性之间的关系四个 预测变量与感知可行性之间调整后 $R$ 方为 0.747 , 共可解释 感知期望变量 $74.7 \%$ 的变异量。教学因素的四个维度对感 知可行性的回归通过了F检验, 显著性为 0.000 , 回归模型 解释变量的水平达到显著。模型的VIF即方差膨胀系数均 是 1 到 2 之间, 变量间没有严重的共线性问题。回归方程中
的 $\alpha$ 为 $2.398 \times 10^{-17}$, 显著性为 1.000 , 标准化系数为 0 , 四个变量均达到显著。四个变量的P均小于 $0.05, \beta$ 分别 为 $0.531 、 0.135 、 0.041 、 0.211$ 。创业竞赛、创业课程、 创业实践基地、师资水平的作用对大学生创业感知可行性 有显著正向作用，假设 $1 \mathrm{~h} 、 1 \mathrm{~d} 、 1 \mathrm{f} 、 1 \mathrm{~b}$ 得到了验证。

表4 系数表C。

\begin{tabular}{|c|c|c|c|c|c|c|}
\hline \multirow{2}{*}{ 模型 } & \multicolumn{2}{|c|}{ 非标准化系数 } & \multirow{2}{*}{$\begin{array}{l}\text { 标准化系数 } \\
\text { Beta }\end{array}$} & \multirow{2}{*}{$\mathrm{T}$} & \multirow{2}{*}{ 显著性 } & \multirow{2}{*}{ VIF } \\
\hline & $\mathrm{B}$ & 标准差 & & & & \\
\hline 3 (常数) & 2. $398 \mathrm{E}-17$ & 070 & & .000 & 1.000 & \\
\hline 教学因素创业竞赛 & .531 & 073 & .531 & 5.000 & .000 & 1.000 \\
\hline 教学因素创业课程 & .135 & 085 & .135 & 3. 613 & .002 & 1.000 \\
\hline 教学因素创业实践基地 & .041 & .078 & .023 & 2. 019 & .014 & 1.000 \\
\hline 教学因素师资水平 & .211 & .075 & .151 & 2. 437 & .006 & 1.000 \\
\hline
\end{tabular}

综上所述, 可以得到以下回归方程:

感知期望 $=0.531 \times$ 创业竞赛 $+0.135 \times$ 创业课程 $+0.041 \times$ 创业实践基地 $+0.211 \times$ 教师水平

个体态度因素与大学生感知可行性之间的关系两个 预测变量与感知可行性之间的调整后R方为 0.753 , 共可解 释感知期望变量 $75.3 \%$ 的变异量。方差分析中, 个体态度 的两个个维度对感知可行性的回归通过了F检验, 显著性 为 0.000 。模型的VIF即方差膨胀系数均是 1 到 2 之间, 变量 间没有严重的共线性问题。由表中的数据可以清楚看到, 回归方程中的非标准化 $\alpha$ 为 $1.823 \times 10^{-17}$, 显著性为
1. 000 , 所以标准化系数为 0 , 个体态度因素达到了显著水 平为 0.000 , 而满意度未达到显著, $\mathrm{P}$ 值为 0.870 。个体态 度参与度的作用对大学生创业感知可行性有显著正向作 用, $\beta$ 为 0.453 , P小于 0.05 , 假设 $2 \mathrm{~b}$ 得到了验证。个体态 度满意度的作用对大学生创业感知可行性不显著, $\beta$ 为 $0.000 ， P$ 大于 0.05 ，假设 $2 \mathrm{~d}$ 未得到验证。

表5 系数表D。

\begin{tabular}{|c|c|c|c|c|c|c|}
\hline \multirow{2}{*}{ 模型 } & \multicolumn{2}{|c|}{ 非标准化系数 } & \multirow{2}{*}{$\begin{array}{l}\text { 标准化系数 } \\
\text { Beta }\end{array}$} & \multirow{2}{*}{$\mathrm{T}$} & \multirow{2}{*}{ 显著性 } & \multirow{2}{*}{ VIF } \\
\hline & B & 标准差 & & & & \\
\hline 4（常数） & 1. $832 \mathrm{E}-17$ & .071 & & .000 & 1. 000 & \\
\hline 个体态度满意度 & .000 & .071 & .000 & .005 & .870 & 1.000 \\
\hline 个体态度参与度 & .453 & .071 & .453 & 4. 232 & .000 & 1.000 \\
\hline
\end{tabular}

综上所述, 可以得到以下回归方程:

感知期望 $=0.000 \times$ 个体态度满意度 $+0.453 \times$ 个体态度参与度

\section{4. 结论}

实证研究结果发现, 除了个人态度中满意度对因变量 的两个维度没有影响外, 其他维度均呈正相关关系, 其中 无论感知可行性还是感知期望, 研究结果均发现教学因素 中的大学生创业竞赛和个人态度中的参与频度对其影响 最大。大学生参与创业教育活动越频繁, 越会激发大学生 的创业感知期望和感知可行性; 大学生对创业教育活动的 举办的情况是否满意, 不会影响大学生的创业感知期望和
感知可行性; 反而大学生积极参与大学生创业竞赛, 会对 激发他们的创业感知期望和感知可行性; 在课堂教学方面, 师资的引领也对激发大学生的创业感知期望和感知可行 性起到重要作用; 在中国, 创业教育实践基地并不完善, 对激发大学生的创业意向有一定作用, 但很微弱。

通过实证研究结论建议应重视大学生创业竞赛以及 学生参与频度, 师资水平会起到一定的作用, 创业教育实 践基地有一些作用但作用不大, 特别注意的是应减少分发 关于满意度的回馈和反馈, 减少不必要的资源浪费。 


\section{参考文献}

[1] Bagozzi R P, Kimmel S K. A comparison of leading theories for the prediction of goal - directed behaviours $[\mathrm{J}]$. British Journal of Social Psychology, 1995, 34 (4) : 437-461.

［2］段锦云. 基于创业事件模型的农民工创业意向 [J]. 数理统 计与管理, 2012, 31 (006):958-964。

[3] 丁明磊, 杨芳, 王云峰. 试析创业自我效能感及其对创业意 向的影响 [J]. 外国经济与管理, 2009 (5) : 1-7。

[4] Thompson E R. Individual entrepreneurial intent: Construct clarification and development of an internationally reliable metric $[\mathrm{J}]$. Entrepreneurship Theory and Practice, 2009, 33 (3): 669-694.

[5] 林崇德, 申继亮, 辛涛. 教师素质的构成及其培养途径 [J]. 中国教育学刊, 1996, 6(2):6。

[6] 蒋京川. 斯腾伯格的智力理论及其应用研究 [D]. 89. 博士学 位论文, 中国学术期刊网, 2007。

[7] Lüthje C, Franke N. The 'making' of an entrepreneur: testing a model of entrepreneurial intent among engineering students at MIT [J]. R\&d Management, 2003, 33 (2) : 135-147.

[8] Liñán F, Chen Y W. Development and Cross - Cultural application of a specific instrument to measure entrepreneurial intentions [J]. Entrepreneurship theory and practice, 2009, 33 (3) : 593-617.

[9] Ajzen I. The theory of planned behavior [J]. Organizational behavior and human decision processes, 1991, 50 (2) : 179-211.

[10] 崔涁, 张亚维. 大学生创业教育满意度及影响因素分析一一 以扬州大学本科生为例 $[\mathrm{J}]$. 扬州大学学报: 高教研究版, 2014 (1) : 67-71。

[11] Allee W C, Murchison C. A handbook of social psychology / [M]. Clark University Press, 1935.

[12] Katz D, Stotland E. A preliminary statement to a theory of attitude structure and change [J]. Psychology: A study of a science, 1959, 3: 423-475.

[13] Chaiken S, Stangor C. Attitudes and attitude change [J]. Annual review of psychology, 1987, 38 (1) : $575-630$.

[14] 李静薇. 创业教育对大学生创业意向的作用机制研究 [D]. 南开大学博士学位论文, 2013。

[15] Chaiken S, Stangor C. Attitudes and attitude change [J]. Annual review of psychology, 1987, 38 (1): 575-630.

[16] Bae T J, Qian S, Miao C, et al. The Relationship Between Entrepreneurship Education and Entrepreneurial Intentions: A Meta-Analytic Review [J]. Entrepreneurship Theory \& Practice, 2014, 38 (2) : $217-254$.

[17] do Paço, A., Ferreira, J. M., Raposo, M., Rodrigues, R. G., \& Dinis, A. Entrepreneurial intentions: is education enough? International Entrepreneurship And Management Journal, 2015, 11 (1), $57-75$.

[18] García-Rodríguez F J, Gil-Soto E, Ruiz-Rosa I, et al. Entrepreneurial intentions in diverse development contexts: a cross-cultural comparison between Senegal and Spain [J]. International Entrepreneurship \& Management Journal, 2013, 11 (3) : 1-17. 